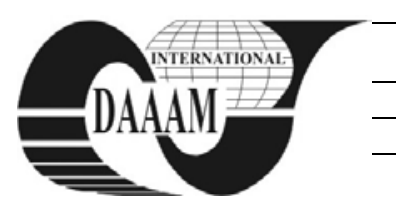

\title{
NATIONAL STRATEGY FOR RESEARCH, DEVELOPMENT AND INNOVATION BY 2013
}

\author{
SIMIONESCU, M[ircea]
}

\begin{abstract}
At the governmental level, where research is financed from public sources, it is imperative to inform society about its importance, and the results obtained from it, so as to enable interested persons (especially decision makers) to monitor further developments and to form their own opinions on the basis of credible scientific information. The public investment in research and development aimed at developing knowledge motivated by socio-economic strategy needs, and research is judged on its innovative capacity.

Key words: research, innovation, budget, competitiveness
\end{abstract}

\section{INTRODUCTION}

With all the negative effect over the research field generated by the current serious economic and financial crisis, the national strategy on research, development and innovation (RDI) projected for 2013 (approved by Government Decision no. 217/2007), remains as the main document supporting the strategic role and the priority position of the field as the engine of economic competitiveness growth and the assurance of sustainable development of the country.

The measures taken to brutally reduce the research budget that was even insufficient for normal development as required by European Union ( $3 \%$ of GDP), touch on the initially established objectives.

A reference, showing the importance of good decision making, is the decision taken by the Finnish government in a moment of acute economic crisis during the early '90s when they had very few financial resources at their disposal. These resources had been directed primarily toward education and research. The results are now recognized in the area of education (international rankings puts Finnish schools on the first place) and in the area of economics (e.g. Nokia).

The following are specific strategic initial objectives for the development of the Research and Innovation Development in Romania during the following years:

\section{STRATEGIC OBJECTIVES}

- The creation of knowledge, respectively the achievement of scientific and technological results, which are internationally competitive.

- The increase of economic competitiveness through innovation with impact at the economic level and the knowledge transfer in economic practice.

- The improvement of the quality of social life, developing solutions, including technology that will generate direct benefits on society.

\section{SPECIFIC OBJECTIVES}

- The development of capacity and increase system performance CDI, both in the public and private sectors, aimed primarily at developing the human capital and the base material for research, to bring them up to a level comparable with the European level.

- The increasing role of research in supporting economic competitiveness increase by stimulating research development and innovation activities and by developing the capacity of dissemination and absorption in the economic knowledge of scientific and technical knowledge, including research results and new technologies.

- Increased international involvement and visibility of the research development and innovation system, through the development and expansion of international cooperation in the field of science in society by strengthening the role of scientific communication, promotion of ethics and developing science-society dialogue.

\section{THEMATIC DIRECTIONS IN THE PUBLIC RESEARCH INVESTMENT}

- Information and Communication Technology - ICT.

- Advanced technology materials and innovative products, including bio-and eco-technologies in the industry, agriculture and food, health, energy, environment, transport, safety and space;

- Socio-economic research.

The public investment in research and development aimed at developing knowledge motivated by socio-economic strategy needs, and research is judged on its innovative capacity, this innovation being the one that provides the stimulus for the creation and maintenance of multiple interfaces between science, technology, society, financial environment, information and policy in a knowledge-based economy.

In most areas established as priorities for public investment in research and development there is also support for thematic directions specific to frontier sciences and fundamental research. Within the priority areas the aim is to create centers of excellence in the form of interdisciplinary research networks and their progressive development as competence centers nationally representative, through the integration of collaborative structures and specific research platforms. The development of capacity and increase of system performance CDI provides:

- The development of human resources for research, so as to achieve a level of expertise to allow the link of knowledge about technical developments worldwide and customization options at national level.

- Research projects will need to ensure the conditions for growth and career research performance of the participants, including domestic and international training courses

- Investment in equipment, especially those of high value, should be considered for the potential use and development of human resources, including being complementary with existing facilities at European level;

- Experimental facilities that support applied research should develop and focus on those areas that can ensure the 
collaboration and partnership between the viable research entities and beneficiaries.

Romania has a total staff engaged in research and development (CD) estimated at over 42,000, of which over $70 \%$ are researchers. CD staff specializes in a range of about 50 scientific and technological areas, including some areas of advanced technologies (for example: Information Technology and Communications, electronics, medicine, pharmaceuticals, aeronautics).

According to the reports taken from the National Authority for Scientific Research, the training and research infrastructure:

- 263 units and institutions for public law research development (R\&D), which are made up of the following national interest R\&D units: 45 R\&D national institutes, 56 accredited public universities, 66 institutes and research centers of the Romanian Academy (52 institutes and 14 research centers), 96 institutes, research and development centers organized as public institutions;

- 32 accredited private universities;

- The network of institutions specialized for technology transfer and innovation, is at this time in the developmental process and currently includes 46 entities located in specific regions of the country as well as four science and technology parks.

- R\&D activities are significantly oriented towards applied areas (according to statistics, about 29\% of funds were spent on $R \& D$ activities in the area of production and industrial technologies). The largest share, about $44 \%$ of researchers in the fields of technical sciences and engineering, represents a favorable support for a faster introduction of advanced technologies in all the economic areas.

The following indicators are used to estimate the impact of the above institutions. These indicators refer to:

1. developing the capacity of the Research Development and Innovation (target values at by the year 2013) through:

- an increase in similar proportion to the total number of researchers, by about 33 000;

- $100 \%$ increase in the number of $\mathrm{PhDs}$ in the science of Innovation Research Development system (of the 8954 presently available)

- an increasing number of researchers in the private sector to more than $100 \%$;

- a $25 \%$ increase in the number of employees in the new units through direct foreign investment in the high-tech sectors ( of the 5500 presently available);

2. The increase of the R D \& I system performance, regarding to the results of high applicability level and of the involvement in major R\&D international projects (target values by the year 2013)

- an increase of the national patents by $200 \%$ of the previous reference values;

- an increase of the international patents by $600 \%$ of the previous values;

- an increase of the transferable products by $100 \%$;

- participation in international projects with $6 \%$ of the R\&D public budget;

\section{CONCLUSIONS}

Romania's strategic directions for action in the area of research, development and innovation presently and in the following years are summarized by the National Authority for Scientific Research as follows:

- Focusing the research efforts towards clearly identified problems, involvement in CDI (research, development and innovation) projects of the representatives' demand, especially those coming from businesses, but also national or regional public authorities;

- Supporting the focus of R \& D resources (human, infrastructure and organizational) in poles of excellence able to compete internationally and to involve collaboration with firms in Romania;

Nine priority areas were selected with a great potential to lead towards economic and social progress, each of them following the evaluation of thematic priorities. The development of experimental facilities to support applied research will focus on those areas that can ensure the collaboration between research entities and beneficiaries.

The investment in equipment, especially of high value, should include the potential of its usage, the development of human resources, as well as its fit to existing facilities in Europe. The development of human resource in the context of national priorities will focus on achieving a level of expertise to permit the correlation of knowledge about technical developments at a global level and the customization possibilities at a national level.

Research projects should provide the conditions for performance recovery in for capitalization on performance recovery for career progress in research participants, ensuring their further development, particularly through national and international training courses.

Romania has proposed a rapid path towards ensuring socioeconomic convergence with the European Union, and it needs the contribution of social and economic sciences in order to ensure rapid adaptation of the education system, of job quality, of filling employment openings, of adequate capacity to absorb technology, while ensuring equality of opportunity. During this time, research in this area must consider the following:

- Identifying and solving major social problems in education, housing and work placement, so that it will consider the elaboration, implementation and evaluation of development of projects at the local, community, regional or national levels that are being centered on;

- Increasing the welfare of individuals;

- Analyzing the social and cultural impact of the communication technologies primarily;

- Elaborating on new management methods of marketing and entrepreneurship development for organizational competitiveness, and finally,

- Identifying the main problems of micro-, mezzo- and macro-economic facing Romania in the context of internationalization and the development of models and methods for their solution.

Innovation and entrepreneurship are needed in the society as much as in economics, in public service institutions and in profit organizations. This happens precisely because innovation and entrepreneurship are not "cause and effect", but "something isolated," a product here, a policy there, public service somewhere else...because they are not planned ahead of time, but used as focus on a particular occasion and a certain need, because these are experimental and will disappear if they do not produce the expected result.

\section{REFERENCES}

Erich A. Helfert, (2006), Techniques of Financial Analysis, Published by BMT Publishing House, Bucharest

NASR, "National Strategy for RDI 2007-2013 ".

PF Drucker, (2000), Innovation and Entrepreneurship, Published by Teora, Bucharest 